\title{
Asimetrías en las cooperativas de crédito españolas
}

\author{
Rafaela Pizarro-Barceló, Ángel García-Ortiz y Ana \\ Lópaz-Pérez
}

\section{RESUMEN}

La crisis financiera actual ha provocado una fuerte reestructuración del sistema bancario español, obligando a las entidades bancarias a adaptarse rápidamente al nuevo entorno regulatorio y económico. En este contexto, las cooperativas de crédito han mostrado un comportamiento diferenciador, no sólo respecto al resto de entidades bancarias sino también entre entidades del mismo sector cooperativo. El objetivo de este artículo es presentar evidencia empírica de la respuesta diferencial de las cooperativas de crédito españolas durante el proceso de reestructuración llevado a cabo desde 2008, en términos de oferta crediticia, rentabilidad, solvencia y eficiencia; mostrando, a su vez, que las asimetrías observadas entre entidades de la banca cooperativa se justifican, principalmente, por su tamaño y grado de capitalización.

PALABRAS CLAVE: Cooperativas de crédito, reestructuración bancaria, sistema institucional de protección, oferta crediticia, rentabilidad, datos de panel.

CLAVES ECONLIT: C230, E510, G010, G210, G340.

Cómo citar este artículo: PIZARRO-BARCELÓ, R., GARCÍA-ORTIZ, A. \& LÓPAZ-PÉREZ, M. (2015): "Asimetrías en las cooperativas de crédito españolas", CIRIEC-España, Revista de Economía Pública, Social y Cooperativa, 84, 101-131.

Correspondencia: Rafaela Pizarro-Barceló, Profesor Doctor del Departamento de Economía y Estadística, Florida Universitaria (Universidad de Valencia), e-mail: rpizarro@florida-uni.es; Ángel García-Ortiz, Profesor Doctor del Departamento de Economía y Estadística, Florida Universitaria (Universidad de Valencia), e-mail: agarcia@florida-uni.es; Ana Lópaz-Pérez, Profesor Doctor del Departamento de Dirección de Empresas y Derecho, Florida Universitaria (Universidad de Valencia), e-mail: alopaz@florida-uni.es. 


\section{Asymétries dans les coopératives de crédit espagnoles}

RÉSUMÉ : La crise financière actuelle a provoqué une forte restructuration du système bancaire espagnol, obligeant les entités bancaires à s'adapter rapidement au nouveau cadre réglementaire et économique. Dans ce contexte, les coopératives de crédit ont montré un comportement différentiateur, non seulement par rapport au reste des entités bancaires mais aussi parmi les entités du même secteur coopératif. L'objectif de cet article est de présenter une preuve empirique de la réponse différentielle des coopératives de crédit espagnoles pendant le processus de restructuration mené depuis 2008 , en termes d'offre de crédit, de rentabilité, de solvabilité et d'efficacité, tout en montrant que les asymétries observées entre les entités de la banque coopérative sont justifiées principalement par leur taille et leur niveau de capitalisation.

MOTS CLÉ : Coopératives de crédit, restructuration bancaire, système institutionnel de protection, offre de crédit, rentabilité, données de panel.

\section{Asymmetries in Spanish credit unions}

ABSTRACT: The current financial crisis has caused a major restructuring of the Spanish banking system, forcing banks to adapt quickly to the new regulatory and economic environment. In this context, credit unions have shown differentiating behaviour, not only compared to other banks but also between members of the same cooperative sector. The aim of this paper is to present empirical evidence for the differential response of Spanish credit unions during the restructuring process carried out since 2008, in terms of credit supply, profitability, solvency and efficiency; showing, in turn, that the observed asymmetries between cooperative banking institutions are explained primarily by their size and degree of capitalisation.

KEY WORDS: Credit unions, bank restructuring, institutional protection scheme, credit supply, profitability, panel data. 


\section{1.- Introducción}

El sistema bancario español, tradicionalmente considerado como uno de los más solventes del mundo, ha mostrado su debilidad en la actual crisis financiera, la cual ha provocado consecuencias negativas para el balance de los bancos, el coste de los fondos y las tasas de rentabilidad, determinando la capacidad de los mismos a la hora de desempeñar la función básica que se le reclama en la salida de la crisis: facilitar el acceso al crédito. Por ello, las autoridades económicas españolas adoptaron un conjunto de medidas de carácter extraordinario orientadas a recuperar la funcionalidad del mismo, facilitar la liquidez, restaurar la confianza y reactivar los mercados. Este conjunto de medidas han provocado una profunda reestructuración del sistema bancario español, especialmente en las cajas de ahorros y en las cooperativas de crédito.

En lo que respecta a la banca española, los bancos pequeños y medianos han tenido serios problemas de financiación debido tanto a la falta de liquidez en los mercados mayoristas como al aumento de la probabilidad de insolvencia; mientras que los grandes bancos, gracias a la consolidación de sus inversiones internacionales, han mostrado una mayor resistencia a las condiciones económicas-financieras adversas, adaptándose rápidamente a los cambios regulatorios y propiciando procesos integradores 0 absorciones de entidades menores y con dificultades de saneamiento.

Por su parte, las cajas de ahorros y las cooperativas de crédito -entidades que conforman lo que se denomina banca social-, con un mayor arraigo territorial pero inmersas en un fuerte proceso de expansión, basado en la apertura de sucursales, en los años precedentes a la crisis, han sufrido en mayor medida el impacto de la crisis financiera.

Mientras que las cajas de ahorros han adoptado intensos sistemas de concentración y de bancarización (Carbó, 2010; Marín, Gras y Antón, 2011; Gutiérrez, Palomo y Fernández, 2013), utilizando, para ello, ayudas públicas; las cooperativas de crédito españolas han emprendido su propia reestructuración, basada, principalmente, en procesos de integración sin acudir a las ayudas del Fondo para la Reestructuración Bancaria Ordenada (FROB) ni recibir fondos públicos (Belmonte y Cortés, 2010; Palomo, Sanchís y Soler, 2010; Gutiérrez y Palomo, 2012).

A pesar del mejor posicionamiento de las cooperativas de crédito a las turbulencias financieras actuales, éstas han sufrido un progresivo desgaste en la cuenta de resultados, consecuencia no sólo de la profunda crisis económica sino también de los últimos cambios regulatorios. Además, la banca cooperativa no debe desdeñar esfuerzos en mejorar sus niveles de eficiencia (Encinas, 2010) y debe continuar reduciendo el grado de atomización del sector y potenciar la generación de recursos recu- 
rrentes que, gracias a la mayor proximidad al cliente y a su mejor conocimiento, se traducen en ampliar la oferta de servicios financieros adecuados a las características particulares de los mismos.

El objetivo de este artículo es presentar evidencia empírica de la respuesta diferencial de las cooperativas de crédito españolas durante el proceso de reestructuración llevado a cabo desde 2008, no sólo respecto al resto de entidades bancarias -bancos y cajas de ahorros- sino también entre entidades del mismo sector cooperativo; mostrando, a su vez, que las asimetrías observadas entre entidades de la banca cooperativa se justifican, principalmente, por su tamaño y grado de capitalización.

Para ello, en primer lugar, se estudia la adaptación de las cooperativas de crédito al nuevo entorno regulatorio y económico surgido de las crisis financiera, destacando, por un lado, los mecanismos de integración adoptados y el cumplimiento de la normativa sobre provisiones y capitalización; y, por otro, las fortalezas observadas en este proceso en términos de rentabilidad, solvencia y empleo y las debilidades mostradas en términos de eficiencia; $y$, en segundo lugar, se analiza el comportamiento asimétrico entre las cooperativas de crédito, según su tamaño y grado de capitalización, en función de sus respuestas en el volumen de crédito ofertado, en el acceso a otras fuentes de financiación no sujetas a reservas y en los ratios de rentabilidad.

El resto del trabajo se estructura como sigue: el apartado 2 analiza el proceso de reestructuración del sistema bancario español desde 2008, indicando las particularidades de las cooperativas de crédito, en términos de actividad productiva, empleo, estructura del balance y márgenes; el apartado 3 presenta una breve revisión de la literatura sobre la importancia que el tamaño y el grado de capitalización tienen para la composición del balance y para la determinación de la oferta crediticia; el apartado 4 presenta dos análisis: por un lado, la segmentación del sector de cooperativas de crédito, según el tamaño y el grado de capitalización, y, por otro, estimaciones econométricas sobre los determinantes de la oferta crediticia, del acceso a otras fuentes de financiación y de la tasa de rentabilidad de las cooperativas de crédito, aportando evidencia del comportamiento diferencial de las mismas; $y$, finalmente, el último apartado expone las principales conclusiones del trabajo. 


\section{2.- Reestructuración del sistema bancario español. El ajuste en las cooperativas de crédito}

\subsection{Principales medidas adoptadas}

A partir de la segunda mitad de 2008 se puso en marcha el último proceso de reestructuración del sistema bancario español. Un proceso claramente fundamentado en factores endógenos ${ }^{1}$, a diferencia de las transformaciones ocurridas con anterioridad.

El inicio de la crisis caracterizado por el cierre de los mercados financieros mayoristas provocó la ralentización en la concesión de crédito y un aumento de las tasas de mora. Sin embargo y a diferencia de otros sistemas bancarios, las autoridades españolas tardaron en reconocer la magnitud del problema.

En este contexto, el proceso regulatorio que se ha aplicado en el sistema bancario español se ha articulado en dos ejes principales: i) reducir el número de entidades, especialmente en las cajas de ahorros y en las cooperativas de crédito, produciéndose una elevada concentración bancaria; y ii) diluir las diferencias institucionales, es decir, la bancarización de las cajas de ahorros ha reducido las entidades de depósitos a dos tipos: bancos (sociedades anónimas) y cooperativas de crédito.

Las fases a lo largo de las cuales se han ido desarrollando las medidas de reestructuración a partir de 2008 quedan agrupadas en cuatro. La primera fase, tuvo por objetivo facilitar el acceso a la liquidez. El primer conjunto de medidas que se adoptaron tenían como prioridad asegurar los depósitos de los ahorradores y facilitar el acceso a la liquidez por parte de las entidades de crédito. $Y$, finalmente, se ofrecieron avales públicos para emisiones de entidades financieras. Ambas medidas pretendían inyectar liquidez a las entidades y evitar las restricciones a la concesión de créditos a familias y empresas.

La segunda fase pretendía consolidar el sector de las cajas de ahorros. Para ello se creó el Fondo para la Reestructuración Bancaria Ordenada (FROB), con el papel de facilitar los procesos de integración mediante la compra de participaciones preferentes de la entidad creada y, además, intervenir en entidades que presentan problemas de viabilidad.

1.- Estos elementos son: fuerte crecimiento del crédito, gran incremento de la actividad, tanto en la apertura de nuevas oficinas como en la expansión de los balances, fuerte dependencia de la financiación mayorista y aumento de los recursos propios de segunda categoría -deuda subordinada- 
Las primeras operaciones de integración en el sector de las cajas de ahorros y de las cooperativas de crédito adoptaron la forma de un Sistema Institucional de Protección ${ }^{2}$ (SIP). La evolución del sector de las cooperativas de crédito ha venido marcada por el proceso de concentración de las entidades que lo componen. Más concretamente, y como señalan un gran número de estudios, el uso de los SIP y las estrategias territoriales son los fenómenos que caracterizan más claramente las decisiones de futuro que debe tomar este sector.

La propia estructura del sector financiero es motivo de la necesaria reordenación de las cooperativas de crédito (Belmonte y Cortés, 2010). Al margen de la crisis, este fenómeno arranca de manera evidente a partir de 1984, momento en el que lo componían 154 entidades, y que ha dado lugar a reducción progresiva hasta alcanzar un número de 81 entidades en 2008. De manera previa al inicio de la reorganización definitiva y especialmente a lo largo del periodo 2000-2008, anterior al recurso de las SIP, las fusiones estuvieron presentes en el sector de las cooperativas de crédito. En la última década, los mismos autores nos apuntan, además, que el proceso de concentración ha sido frecuente y similar al que se ha producido en el resto de Europa.

Aunque inicialmente se establecieron seis SIP's en las cajas de ahorros -Banca Cívica, BFABankia, Banco Mare Nostrum, Liberbank, Banco Caja 3 y Kutxabank- la dificultad en el acceso a la financiación debido a la falta de reconocimiento de los mercados de dichos grupos, obligó a la integración total, cediendo las entidades participes sus activos y pasivos a la entidad central creada con la SIP.

Diferentes trabajos coinciden en señalar la idoneidad del instrumento SIP para las cooperativas de crédito y cajas de ahorro. El arraigo cultural y territorial, y un modelo de negocio minorista, descentralizado y subsidiario de claro espíritu social son rasgos que permiten su aplicación a ambas figuras, sobre todo a las primeras. No es extraño, por tanto, que en la búsqueda de generar ganancias de solvencia y estabilidad financiera, así como en la búsqueda de mayor eficiencia que las haga más competitivas, la SIP haya sido un instrumento de uso mayoritario en el proceso de concentración y reestructuración ${ }^{3}$.

El resultado del proceso de concentración derivado del uso de las SIP ha acumulado un conjunto de rasgos interesantes. En primer lugar, ha desbordado el ámbito tradicional de lo territorial, superando la circunscripción histórica de la provincia o comarca. Pero, además, parece evidente que tampoco han respetado del todo criterios de homogeneidad de negocio (Gutiérrez et al., 2013). Como

2.- A partir de la Directiva 2006/48/CE, de acceso a la actividad de las entidades de crédito, y una vez traspuesta al ordenamiento jurídico español a través de diversas normas surge la figura de las SIP. También conocidas como "fusión fría", esta fórmula pretenderá que entidades con negocios y actividades homogéneas, y con la posibilidad de ponderar al $0 \%$ sus riesgos internos, lleven a cabo procesos de concentración empresarial. Esta fórmula permite mantener la independencia jurídica y operativa, y también la marca; generando sinergias de alto valor entre las entidades asociadas.

3.- Las entidades cooperativas pueden valorar distintos enfoques en la consecución de los objetivos pretendidos. Tres enfoques deben señalarse: a) enfoque solvencia, b) enfoque estratégico y c) enfoque de dirección y gestión de riesgos. 
señalan estos autores pueden encontrase otros criterios no exclusivamente económicos y de valoración subjetiva; a saber: afinidades personales entre sus principales responsables; mejores relaciones tradicionales; posicionamientos estratégicos similares o compartidos en la actualidad y en el pasado; ausencia de rivalidad o conflictos anteriores; etc., lo cual ratifica la idea de que las operaciones de concentración empresarial no sólo pueden ser valoradas mediante indicadores puramente económicos. Los criterios personales son un factor clave. El resultado de estas operaciones de consolidación ha sido una reducción en el censo de entidades de depósito, tal y como se recoge en el gráfico 1.

\section{Gráfico 1. Número de entidades de depósito en el Sistema Bancario Español}

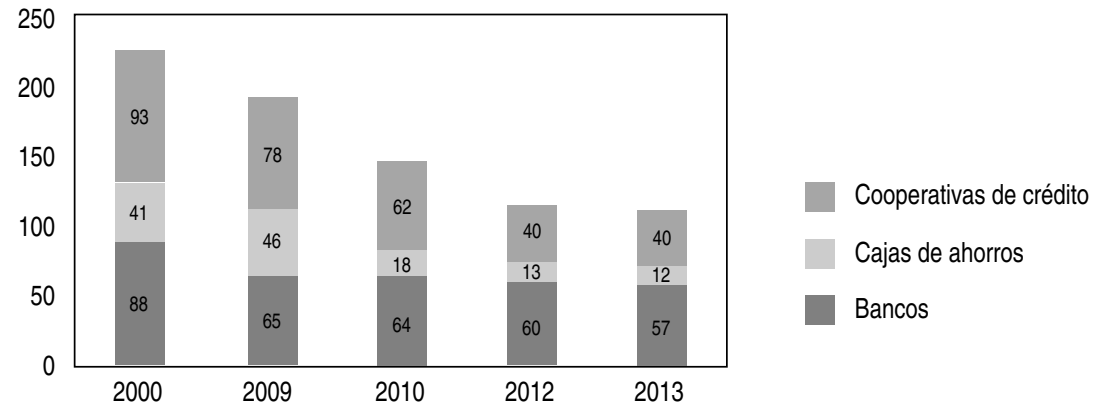

FUENTE: Banco de España, Unacc, CECA, AEB. Elaboración propia.

La tercera fase fijó como objetivo la mejora de los ratios de solvencia de las entidades de depósito. En esta dirección y entre 2010 y 2011 , dos medidas serían las protagonistas; por un lado se incrementaron las exigencias de transparencia a las entidades financieras -referidas a la cartera de activos inmobiliarios-, y, por otro, se elevaron los requerimientos de capital de las entidades.

En la fecha de entrada en vigor de este último decreto ley el total de las cooperativas de crédito cumplía y superaba el requisito impuesto por el Banco de España, ya que cuenta con una amplia base societaria que agrupa a más de dos millones setecientos mil de socios, observándose un crecimiento del 8\% entre 2012 y 2013, el mayor de todo el periodo (gráfico 2). 


\section{Gráfico 2. Total socios en las cooperativas de crédito}

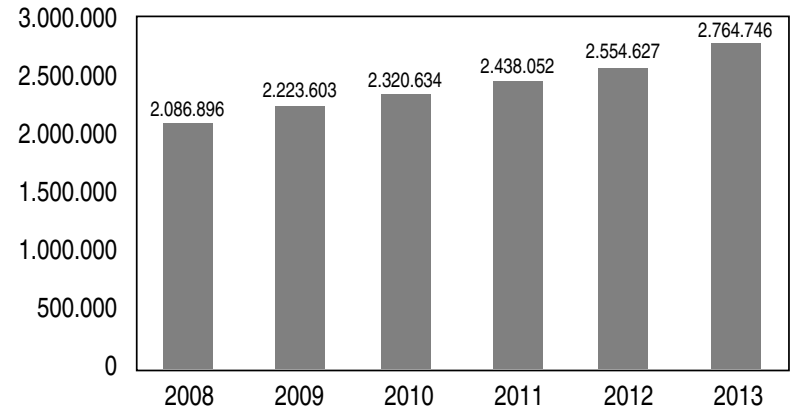

FUENTE: Unacc. Elaboración propia.

La última y cuarta fase tiene como objetivo el saneamiento de los balances de las entidades crediticias. Los Reales Decretos-Ley 2/2012 y 18/2012 fueron aprobados para acelerar el saneamiento de los activos más problemáticos, los referidos a la construcción y promoción inmobiliaria. Es en este momento cuando se resolvió finalmente solicitar a los Estados miembros de la zona euro, aprobado con el Memorando de Entendimiento (Memorandum of Understanding o MoU), una inyección de capital al sistema, a través del FROB.

En definitiva, los cambios regulatorios que las autoridades españolas ha adoptado para hacer frente a la crisis financiera internacional han supuesto una profunda reestructuración del sistema bancario español, cuyas consecuencias se pueden sintetizar en una reducción del número de entidades, en un aumento en las provisiones y en las exigencias de capital para reducir el riesgo asociado a la cartera inmobiliaria y para mejorar la solvencia de las entidades españolas y, finalmente, en una mejora de la calidad de los balances, transfiriendo los activos tóxicos al "banco malo" (SAREB). En lo que respecta a la banca cooperativa, se puede concluir que las cooperativas de crédito presentan un mejor posicionamiento a las turbulencias financieras actuales, llevando a cabo los procesos de integración requeridos sin ayudas públicas, con una menor exposición al riesgo inmobiliario y cumpliendo las nuevas exigencias de capital, gracias al aumento de su base societaria. 


\subsection{El ajuste reciente en el sector de cooperativas de crédito}

En el presente apartado se analiza la evolución reciente del sector de cooperativas de crédito 4 dentro de este marco de reformas y de reestructuración. Si bien es un sector que sólo representa una cuota de mercado, a nivel nacional y agregado, del crédito del 6,12\% y de los depósitos del 6,95\% -datos referidos a marzo de 2014-, adquiere relevancia a nivel local, ya que el $60 \%$ de las cooperativas están ubicadas en municipios con menos de 25.000 habitantes.

\section{Actividad productiva y empleo}

El proceso de consolidación del sistema bancario español en los últimos 5 años ha reducido el número de entidades de depósito (véase el gráfico 3), afectando también al sector de cooperativas de crédito: de 81 cooperativas que habían en 2008 a 68 (o 40 grupos consolidables) en 2013. La consecuencia de los procesos de integración comentados en el apartado anterior ha sido una reducción tanto en el número de oficinas como en el número de empleados (gráfico 3), si bien se ha mantenido la ratio empleado por oficina en 4 (ligeramente inferiores al 4,7 que presentan bancos y cajas de ahorros). Señalar que, comparativamente, si bien esta evolución coincide con el resto de entidades de depósito, el ritmo es menor: por un lado, el número de oficinas de las cooperativas de crédito se ha reducido un $9 \%$ en el período analizado mientras que en bancos y cajas de ahorros ha sido de un $14,4 \%$; y por otro, el empleo ha disminuido un $9,6 \%$ en las cooperativas frente a un $11 \%$ en bancos y cajas de ahorros.

\section{Gráfico 3. Empleo y oficinas}

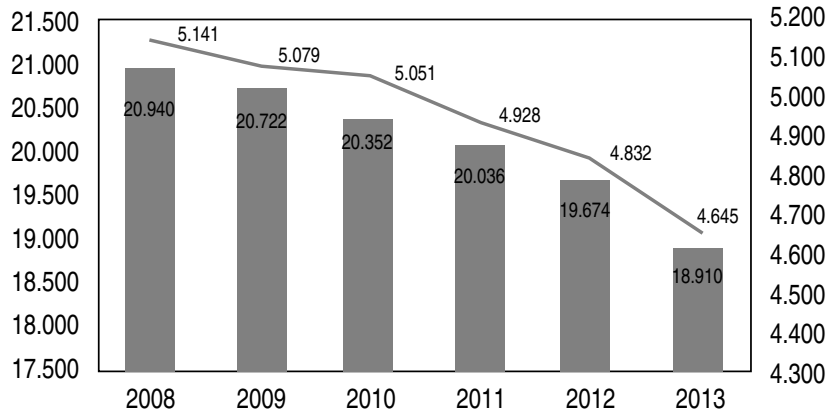

FUENTE: Unacc. Elaboración propia. 
Sin embargo, este proceso de ajuste de la estructura productiva no ha afectado negativamente a la actividad bancaria, ya que el nuevo mapa de cooperativas de crédito -compuesto por entidades de mayor tamaño- permite generar economías de escala para reducir gastos y acceder con mayor facilidad a los mercados financieros con un menor coste. Como se aprecia en el gráfico 4 , el activo total en 2013 es 1,6 veces mayor que en 2008, mientras que los créditos y los depósitos son 1,36 y 1,44 veces superiores respectivamente. Sin embargo, hay que señalar una ralentización del output bancario en 2012, ya que los créditos sólo aumentan un 1,6\% mientras que los depósitos descienden un $0,44 \%$.

\section{Gráfico 4. Activo total, créditos y depósitos}

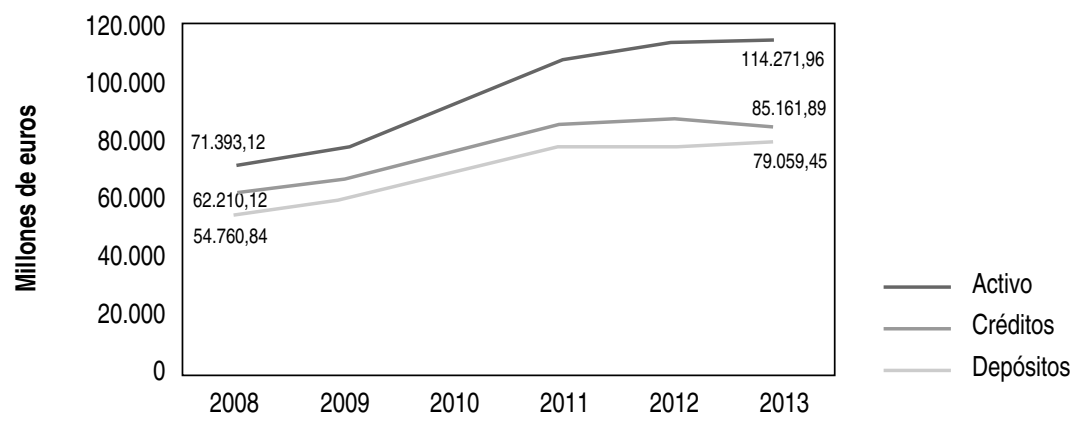

Nota: los depósitos recogen sólo los "depósitos de la clientela".

FUENTE: Unacc. Elaboración propia.

\section{Estructura del balance}

La composición del balance de las cooperativas de crédito refleja las estrategias de negocio aplicadas en las operaciones de activo y de pasivo. Por el lado del activo, la concesión de créditos es la principal actividad de las cooperativas de crédito, aunque su peso relativo se ha reducido en 10 puntos porcentuales debido, principalmente, a la disminución relativa de los créditos a la clientela provocada por el desapalancamiento de hogares y empresas. No obstante, el peso de los créditos a otros sectores residentes es superior al 58,4\%, la media del conjunto de entidades de depósito en 2013. 


\section{Tabla 1. Balance de las cooperativas de crédito (\% sobre el activo)}

\begin{tabular}{|l|rrrrrr|}
\hline & $\mathbf{2 0 0 8}$ & $\mathbf{2 0 0 9}$ & $\mathbf{2 0 1 0}$ & $\mathbf{2 0 1 1}$ & $\mathbf{2 0 1 2}$ & $\mathbf{2 0 1 3}$ \\
\hline ACTIVO & $\mathbf{1 0 0 , 0 0}$ & $\mathbf{1 0 0 , 0 0}$ & $\mathbf{1 0 0 , 0 0}$ & $\mathbf{1 0 0 , 0 0}$ & $\mathbf{1 0 0 , 0 0}$ & $\mathbf{1 0 0 , 0 0}$ \\
\hline Caja y depósitos en bancos centrales & 2,25 & 1,44 & 0,84 & 0,97 & 0,91 & 0,82 \\
Cartera de negociación & 0,09 & 0,18 & 0,10 & 0,23 & 0,39 & 0,35 \\
Otros activos financieros a valor razonable & 0,10 & 0,07 & 0,09 & 0,04 & 0,02 & 0,04 \\
Activos financieros disponibles para la venta & 5,90 & 7,64 & 8,81 & 11,03 & 10,36 & 14,13 \\
Inversiones crediticias & 87,14 & 85,49 & 83,53 & 79,98 & 76,92 & 74,53 \\
$\quad$ Del que: Crédito a la clientela & 83,09 & 80,14 & 79,51 & 73,89 & 68,65 & 66,17 \\
Participaciones & 0,26 & 0,22 & 0,18 & 0,13 & 0,14 & 0,13 \\
Activo material & 2,07 & 2,07 & 2,16 & 2,06 & 1,95 & 1,87 \\
Resto activo & 2,19 & 2,90 & 4,29 & 5,56 & 9,31 & 8,14 \\
\hline PASIVO & 92,75 & 92,28 & 92,52 & 92,54 & 93,83 & 93,20 \\
\hline Cartera de negociación & 0,03 & 0,07 & 0,05 & 0,08 & 0,16 & 0,18 \\
Otros pasivos financieros a valor razonable & 0,06 & 0,04 & 0,03 & 0,05 & 0,04 & 0,02 \\
Pasivos financieros a coste amortizado & 90,84 & 90,37 & 90,82 & 90,87 & 91,83 & 91,27 \\
Depósitos de bancos centrales & 4,05 & 2,76 & 1,53 & 4,44 & 8,61 & 8,06 \\
Depósitos de entidades de crédito & 4,08 & 4,67 & 7,14 & 9,70 & 11,56 & 10,60 \\
Depósitos de la clientela & 76,70 & 77,33 & 76,66 & 73,00 & 68,71 & 69,19 \\
Débitos representados por valores negociables & 4,66 & 4,51 & 4,49 & 2,84 & 1,94 & 2,57 \\
Pasivos subordinados & 0,48 & 0,43 & 0,35 & 0,17 & 0,15 & 0,12 \\
Otros pasivos financieros & 0,87 & 0,68 & 0,64 & 0,70 & 0,87 & 0,73 \\
Provisiones & 0,23 & 0,23 & 0,17 & 0,16 & 0,30 & 0,29 \\
Resto pasivo & 8,84 & 9,29 & 8,93 & 8,84 & 7,67 & 8,24 \\
\hline PATRIMONIO NETO & $\mathbf{7 , 2 5}$ & $\mathbf{7 , 7 2}$ & $\mathbf{7 , 4 8}$ & $\mathbf{7 , 4 6}$ & $\mathbf{6 , 1 7}$ & $\mathbf{6 , 8 0}$ \\
\hline Del cual: Fondos propios & 7,61 & 7,86 & 7,62 & 7,65 & 6,15 & 6,50 \\
\hline PASIVO Y PATRIMONIO NETO & $\mathbf{1 0 0 , 0 0}$ & $\mathbf{1 0 0 , 0 0}$ & $\mathbf{1 0 0 , 0 0}$ & $\mathbf{1 0 0 , 0 0}$ & $\mathbf{1 0 0 , 0 0}$ & $\mathbf{1 0 0 , 0 0}$ \\
\hline
\end{tabular}

FUENTE: Unacc. Elaboración propia.

Además, se observa una mayor diversificación del activo, ya que las cooperativas de crédito también invierten en valores monetarios, de renta fija y de renta variable (Cartera de negociación, Otros activos financieros a valor razonable y Activos financieros disponibles para la venta), pasando a representar un 6\% en 2008 a cerca de un 15\% en 2013, gracias, sobre todo, a la adquisición de activos monetarios que son aceptados como colateral por el BCE en sus operaciones monetarias y para acceder a la financiación en los mercados monetarios. Respecto al resto de entidades de depósito, ambas partidas rondan entre un $15 \%$ en 2008 y un $26 \%$ en 2013 , superiores a las presentadas por las cooperativas de crédito. 
En lo que respecta al pasivo, los depósitos siguen siendo la principal fuente de financiación de las cooperativas de crédito -entre el $90 \%$ y $92 \%$-, aunque sí se percibe un cambio a favor de los recursos obtenidos de bancos centrales -de 4,05\% en 2008 a 8,06\% en 2013-y de otras entidades de crédito - de 4,08\% en 2008 a 10,60\% en 2013-, reduciéndose claramente el ahorro captado de las familias y empresas a través de otros instrumentos financieros: "débitos representados por valores negociables" y "pasivos subordinados". Hay que destacar, además, el aumento del peso relativo de la "cartera de negociación", la cual recoge la emisión de valores para apelar a la financiación en los mercados mayoristas -sensiblemente inferior al 4\% en 2013 para el resto de entidades de depósito-.

Sin embargo, a pesar del esfuerzo realizado por las cooperativas de crédito de cumplir con las nuevas exigencias de capital analizadas en el apartado anterior, el incremento en las dotaciones de capital y reservas se ha visto contrarrestado por una reducción en los resultados del ejercicio, disminuyendo el ratio fondos propio/activo y aumentando, por tanto, el apalancamiento de las cooperativas de crédito: el activo era 13 veces mayor que los fondos propios en 2008, mientras que pasa a ser 15 veces mayor en 2013. Tendencia contraria al resto de entidades del sistema bancario (ver gráfico 5).

\section{Gráfico 5. Aportaciones de capital de las cooperativas de crédito}
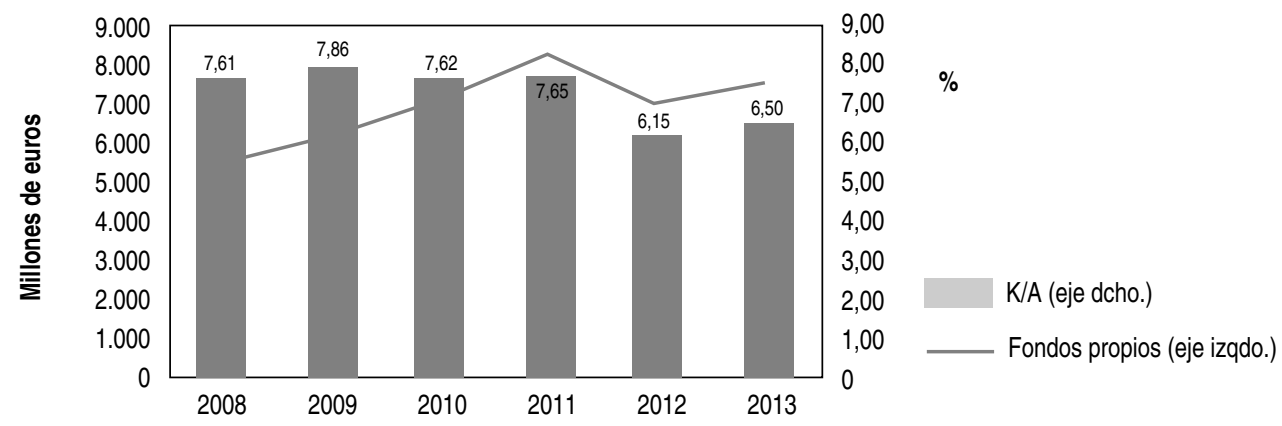

FUENTE: Unacc. Elaboración propia.

Por último, para concluir el análisis de la estructura del balance y dada la importancia de las operaciones crediticias, es imprescindible que las cooperativas de crédito realicen una buena gestión del riesgo crediticio. La tabla 2 muestra la morosidad y la solvencia de los 4 grandes grupos cooperativos: Cajamar, Caja LaboralKutxa, Grupo Ibérico y Bantierra. Respecto a la tasa de morosidad, la tasa media de los 4 grupos (12,47\%) se mantiene por debajo de la media de las entidades de depósito $(13,77 \%)$, aunque hay que señalar el caso de Cajamar con un ratio sensiblemente superior; sin embargo, en la tasa de cobertura de los créditos morosos todos los grupos se mantienen por debajo de la media del sector bancario (116,04\% en 2012). Destacar, finalmente, que los cuatro grupos considerados cumplen ampliamente con el ratio de solvencia exigido por las autoridades ( $9 \%)$. 


\section{Tabla 2. Tasas relacionadas con el riesgo crediticio para los 4 grandes grupos cooperativos, 2013}

\begin{tabular}{|l|ccc|}
\hline & Tasa de morosidad & Ratio de solvencia & Tasa de cobertura de dudosos \\
\hline Cajamar & 17,15 & 11,29 & 43,64 \\
Caja LaboralKutxa & 9,68 & 12,92 & - \\
Ibérico (a) & 11,44 & 13,08 & 73,76 \\
Bantierra (a) & 11,63 & 9,14 & 87,02 \\
\hline
\end{tabular}

(a) Datos referidos a 2012.

FUENTE: Informes de Relevancia Prudencial de cada entidad. Elaboración propia.

\section{Análisis de la cuenta de resultados: márgenes y ratios de rentabilidad}

En la tabla 3 y gráfico 6 se presenta la cuenta de resultados del sector de cooperativas de crédito durante el período 2008-2013. El margen de intereses presenta una trayectoria decreciente, reflejando, por un lado, unos menores ingresos por las inversiones rentables debido a la caída de los tipos de interés y al descenso en el ritmo de concesión de créditos nuevos y, por otro, una disminución en los costes financieros, dadas las dificultades de las entidades de obtener financiación en los mercados mayoristas. Sin embargo, de 2012 a 2013 se observa un cambio de tendencia de ligera recuperación.

\section{Gráfico 6. Resultados sobre ATM de las cooperativas de crédito}

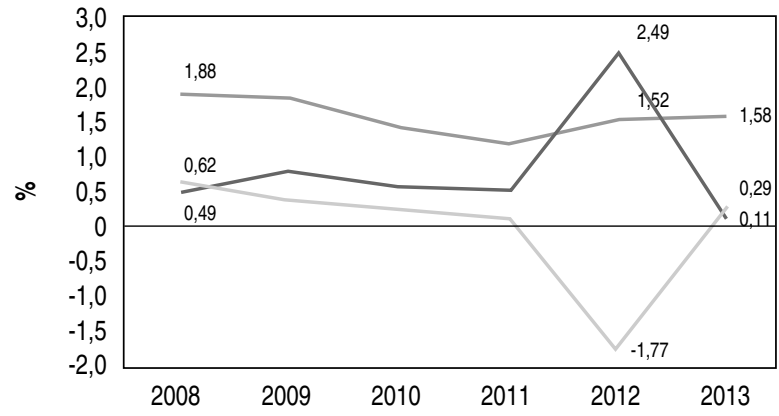

_ Margen de intereses

_ Pérdidas por deterioro de activos Resultado antes de impuestos

FUENTE: Unacc. Elaboración propia.

A diferencia del margen de intereses, otros productos financieros han seguido una senda alcista gracias al incremento de las comisiones percibidas, aunque su peso relativo se mantiene. Por ello, el margen bruto en términos absolutos es creciente en todo el período. 
Sin embargo, basadas en ajustes de plantilla y disminución de la red de oficinas, los gastos de explotación no se han reducido lo suficiente para compensar el estrechamiento de márgenes. Si a esto se añade el incremento de la morosidad, el aumento de los activos adjudicados, la caída de la actividad económica, el deterioro del mercado laboral y el cambio regulatorio sobre nuevas exigencias de capital para el saneamiento de los balances (véase el apartado anterior), se entiende el aumento de las provisiones por pérdidas de deterioro de activos -siendo considerable en 2012- y, consecuentemente, sus efectos sobre los beneficios antes de impuestos, los cuales han ido disminuyendo, llegando a ser negativos en 2012. Este efecto desaparece al no imputarse en el siguiente ejercicio las dotaciones permitiendo una clara recuperación a lo largo de 2013, con una variación positiva del 116,3\%.

\section{Gráfico 7. Eficiencia operativa de las cooperativas de crédito}

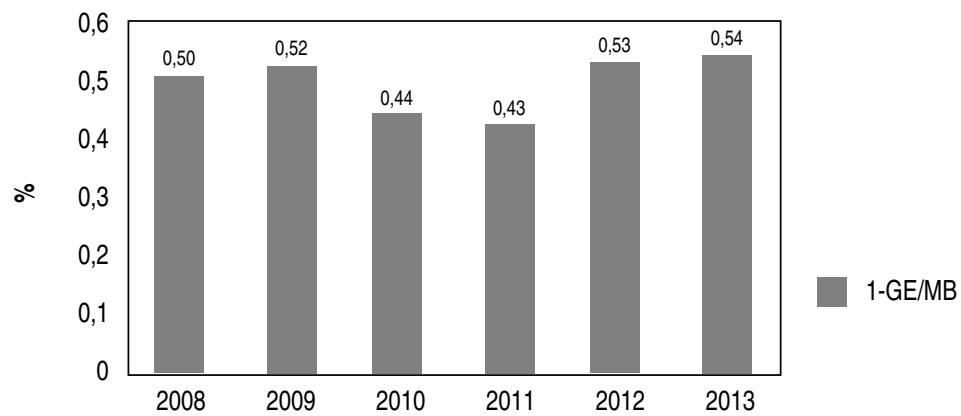

FUENTE: Unacc. Elaboración propia.

En definitiva, la reducción del nivel de ingresos, como consecuencia de una caída en el volumen de negocio por la crisis económica actual, junto con las pérdidas por el deterioro de los activos, hace imprescindible un intenso control de los gastos de explotación. A pesar de la mejoría mostrada en el conjunto del sector cooperativo (véase el gráfico 7 donde se percibe una mejoría en la eficiencia operativa (1 - Gastos de Explotación/Margen Bruto), la reducción de coste sigue siendo un objetivo fundamental. Además, es necesario intensificar el proceso de desapalancamiento, iniciado por los mayores requerimientos de capital impuestos por las autoridades, para retomar unas tasas de rentabilidad positivas. 


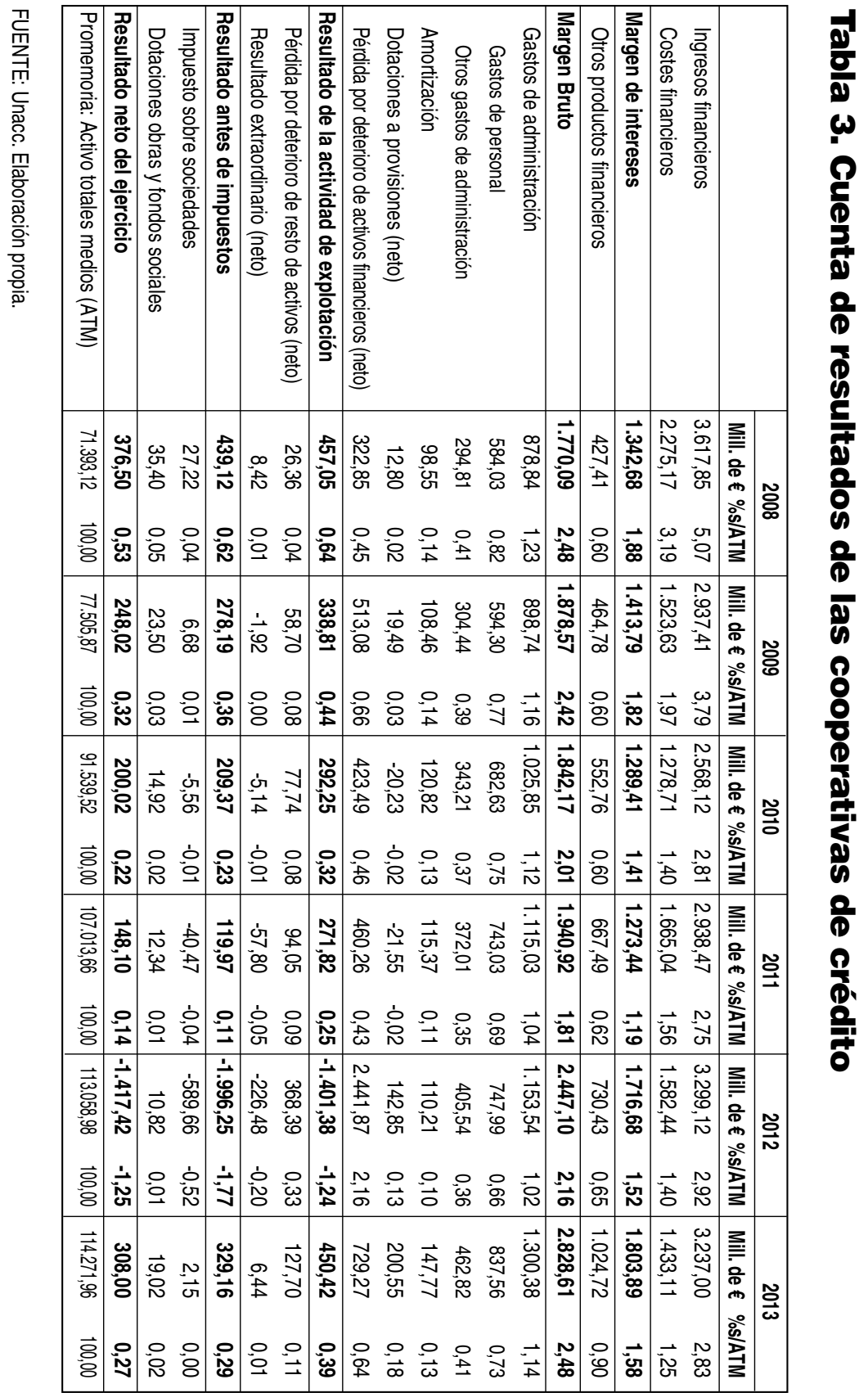




\section{3.- Tamaño y capitalización: efectos sobre el balance de las entidades bancarias}

La adecuación a un entorno adverso de crisis financiera internacional, de falta de liquidez y de estancamiento económico, junto con un cambio regulatorio, en términos de requerimientos de capital y de dotaciones a provisiones, ha conducido el proceso de transformación en el sector de cooperativas de crédito, descrito anteriormente.

Esta reestructuración se ha basado, por un lado, en mecanismos de fusión y de integración, aumentando la concentración del sector y, por otro, en ajustes en el balance con los consiguientes efectos sobre la cuenta de resultados de las cooperativas.

¿En qué medida el mayor tamaño de las cooperativas de crédito y su creciente capitalización pueden modificar, entre otros aspectos, la oferta de crédito, la captación de fuentes alternativas de financiación y la generación de márgenes?

Existe una amplia literatura centrada en analizar la respuesta heterogénea, en términos de oferta crediticia y de otras formas de financiación, de las entidades bancarias ante shocks monetarios -canal del crédito bancario-, basada en la fundamentación teórica consistente, por un lado, en la existencia de problemas de información asimétrica y de selección adversa en el mercado de capitales -(Bernanke y Blinder, 1988; Romer y Romer, 1990; Kashyap, Stein y Wilcox, 1993)-, y, por otro, en el racionamiento en el mercado de crédito -(Stiglitz y Weiss,1981 y King, 1986)-.

Utilizando esta modelización teórica y desde un enfoque microeconómico, son muchos los estudios empíricos que analizan el impacto del tamaño y del grado de capitalización sobre la oferta crediticia 5 .

El tamaño se considera una variable proxy de los problemas de selección adversa a los que se enfrenta un banco y, por tanto, de la capacidad para poder acceder a otras formas de financiación no sujetas a los requerimientos de reservas. Así, el volumen de crédito de los bancos pequeños se contrae mucho más que el de los bancos grandes ante un shock adverso, como consecuencia del alto grado de información asimétrica al que se enfrentan (Kashyap y Stein, 1995).

El grado de capitalización es un indicador de la solvencia de un banco y determina la facilidad de un banco para compensar una reducción en sus depósitos a través de otras vías de financiación.

5.- Algunos trabajos han analizado el nivel de liquidez de una entidad bancaria como determinante de la respuesta heterogénea en la oferta de crédito, encontrando resultados ambiguos (véase Kashyap y Stein, 2000), por ello, el grado de liquidez se recogerá sólo como variable explicativa en las especificaciones del apartado 4, y no como criterio para clasificar a las cooperativas de crédito. 
La literatura reciente sobre las dificultades crediticias ("credit crunch") se ha centrado en analizar el efecto del nivel de capital bancario sobre el crecimiento en la producción y en los créditos, ya que éste presenta una restricción a la capacidad de los bancos para prestar fondos en forma de créditos.

Tanto el nivel de capitalización como la regulación bancaria sobre recursos propios tienen un doble efecto (Van den Heuvel, 2002): en primer lugar, si los bancos deben mantener una dotación de capital como porcentaje de sus activos arriesgados y si la emisión de nuevas acciones es costosa para un banco (debido a los problemas de información asimétrica que acompañan a la emisión de nuevas acciones), entonces los bancos preferirán poseer más títulos u obligaciones no sujetos a este requerimiento que invertir en nuevos créditos (activo arriesgado), reduciéndose la financiación bancaria para los gastos de consumo e inversión, con el consiguiente efecto sobre la producción; en segundo lugar, el capital bancario mitiga los problemas de selección adversa en el mercado de otros pasivos bancarios no sujetos a reservas, siendo menos costoso amortiguar un shock negativo en las reservas sin alterar el crédito ofrecido. Resumiendo, la respuesta de la oferta crediticia tras un shock adverso será menor cuanto 1) mayor sea el porcentaje de bancos que no cumplan el mínimo de capital requerido 0 2) mayor sea el porcentaje de bancos adecuadamente capitalizados con una alta ratio de capital.

Teniendo en cuenta ambas dimensiones, Kishan y Opiela (2000) proponen un modelo teórico para medir la respuesta diferencial en la oferta de crédito entre bancos en función de su tamaño y nivel de capitalización. En éste se analizan los efectos de una contracción monetaria sobre las partidas del balance de una empresa bancaria representativa: por el lado del activo, se incluyen los créditos, obligaciones y reservas, y, por el lado del pasivo, depósitos, otras formas de financiación no sujetas a reservas y el capital.

La evidencia empírica de este último enfoque aportada para Estados Unidos es bastante concluyente: por un lado, Thakor (1996) demuestra que la adopción de los acuerdos sobre requerimientos de capital de Basle (BIS) en 1989 y 1992 redujo la oferta agregada de crédito; y, por otro, Kishan y Opiela (2000) obtienen que la reducción de la oferta crediticia es menor en los bancos más grandes y más capitalizados.

Sin embargo, para UE y en especial para España, aparece cierta vaguedad en los resultados obtenidos. Destaca el trabajo de Ehrmann et al. (2001), el cual establece que la oferta de crédito intermediado se reduce más tras un shock monetario negativo en los bancos más pequeños 0 en los menos líquidos o en los que tienen una menor ratio de capital. Sin embargo, sólo se demuestra que el nivel de liquidez influye en la oferta de crédito diferencial, exceptuando España que tampoco dicha variable es significativa 6 .

6.- Algunas justificaciones a dicho resultado pueden ser: i) la adopción del supuesto de homogeneidad en la demanda de crédito entre bancos, ya que se supone que las grandes empresas -clientes de los grandes bancos- no encuentran sustitutivos para la financiación bancaria; ii) el tamaño no parece ser un buen indicador de los problemas de selección adversa y, por tanto, de la capacidad de acceder a otras formas de financiación distintas a los depósitos; iii) la medida de capitalización utilizada, (Capital + Reservas) / Activo, no permite capturar el riesgo de la cartera de créditos de un banco, ni reflejar correctamente los problemas de información asimétrica. 
Para el sistema bancario español, Hernando y Martínez-Pagés (2001) aportan evidencia ambigua, ya que, por un lado, los bancos más pequeños responden más fuertemente reduciendo su oferta de crédito y, por otro, los bancos más capitalizados contraen más su crédito. Mientras que Pizarro-Barceló (2011), utilizando datos desagregados para la banca española, obtiene una respuesta diferencial en el comportamiento de la oferta crediticia, ya que ésta se reduce más cuanto menor es el grado de capitalización, menor la liquidez y menor el tamaño de un banco.

\section{4.- Evidencia empírica de la respuesta diferencial de las cooperativas de crédito a la crisis actual}

El presente apartado aporta evidencia del comportamiento asimétrico de las cooperativas de crédito durante el período de crisis, 2008-2013, haciendo hincapié si los dos fenómenos observados en el actual proceso de reestructuración bancaria -entidades de mayor tamaño y más capitalizadas- han repercutido en la respuesta heterogénea de las cooperativas de crédito.

Para ello, se presenta, en primer lugar, una caracterización de la estructura del balance del sector español de cooperativas de crédito, distinguiendo a las entidades por tamaño y nivel de capitalización; y, posteriormente, se detallan los resultados de la estimación de un modelo econométrico para contrastar la respuesta diferencial de las cooperativas de crédito en términos de oferta crediticia, acceso a otras fuentes de financiación y rentabilidad.

\subsection{Análisis descriptivo de la segmentación de las cooperativas de crédito, según el tamaño y el grado de capitalización}

Los datos sobre las partidas relevantes del balance de las cooperativas de crédito proceden de los balances consolidados anuales de las cooperativas de crédito asociadas a Unacc, las cuales representan alrededor del $80 \%$ del total de cooperativas españolas. La base original ha sido depurada ${ }^{7}$ para obtener un panel equilibrado de 15 cooperativas y/o grupos cooperativos, con un total de 90 observaciones.

Según las dos características relevantes para determinar el comportamiento de las cooperativas de crédito durante el periodo de crisis -el tamaño del activo y el nivel de capitalización-, se dividen las cooperativas de crédito de la siguiente forma:

7.- No se ha tenido en cuenta aquellas entidades que no aportasen sus balances todos los años, ni las que hayan sido absorbidas por otra. En el panel se incluyen cuatro SIPs (Grupo Cooperativo Cajamar, Grupo Cooperativo Ibérico, Nueva Caja Rural de Aragón y Grupo Cooperativo Solventia) y tres fusiones (Caja Laboral, Bantierra y Globalcaja). 
- Según el tamaño del activo, en cinco grupos establecidos por los siguientes percentiles8: <p25 (< 1.660 millones de $€$ ), p25-p50 (1.660 millones de $€-2.691$ millones de $€$ ), p50-p75 (2.691 millones de $€-5.991$ millones de $€$ ), p75-p90 (5.991 millones de $€-16.725$ millones de $€$ ) $y \geq p 90$ ( $\geq 16.725$ millones de $€$ ) (Véase la tabla 4 ).

- Según la ratio $K / A^{9}$, se desglosan las entidades en dos grupos: infracapitalizadas $(K / A<8 \%)$ y adecuadamente capitalizadas ( $8 \% \leq K / A)$ (Véase la tabla 5$)$.

Las tablas 4 y 5 muestran la cuota de mercado y la estructura del balance para cada grupo, de las cuales se puede deducir los siguientes aspectos:

- Según el tamaño del activo:

i) Sólo dos cooperativas de crédito -Caja Laboral y Cajamar- concentran el 60\% del mercado en el total del activo, en los créditos a la clientela y en los depósitos a la clientela; mientras que las de menor tamaño (<p25 y p25-p50) abarcan alrededor del 10\%. Este hecho evidencia la alta concentración que se ha producido en el sector de cooperativas de crédito durante el período de crisis.

ii) Respecto a la composición del activo, las cooperativas más pequeñas (<p25 y p25-p50) mantienen un porcentaje mayor de títulos -obligaciones a corto y préstamos interbancarios (cartera de negociación), obligaciones a largo y valores de renta variable (otros activos financieros a valor razonable y activos financieros disponibles para la venta)- $\mathrm{y}$ un porcentaje menor de créditos a otros sectores residentes (crédito a la clientela) que las más grandes.

iii) Respecto a la composición del pasivo, no se encuentran diferencias significativas en función del tamaño respecto a la obtención de recursos, ya que, por un lado, las cooperativas de mayor tamaño (>p90) y de tamaño pequeño (p25 - p50) mantienen un mayor porcentaje en los depósitos de la clientela y en otras formas de financiación no sujetas a requerimientos de reservas (los depósitos de bancos centrales, pasivos subordinados y otros pasivos financieros); $y$, por otro, el resto de cooperativas mantienen una mayor proporción en la captación de financiación de otras entidades de crédito (depósitos de entidades de crédito).

iv) Respecto a la capitalización, no existe relación entre el tamaño de la cooperativa y su dotación de fondos propios; destacando el bajo nivel de capitalización del sector cooperativo y que las cooperativas más grandes (>p90) son las menos capitalizadas.

- Según el grado de capitalización:

i) El $73 \%$ de las entidades tienen una ratio inferior al $8 \%$ y suponen cerca del $82 \%$ de la cuota de mercado.

ii) La cooperativa de crédito más capitalizada es CR Jaén (p25-p50) con 9,55\%, seguida de CR Navarra (p75-p90) con 8,75\%, CR Soria (<p25) y CR Sur (p75-p90) con $8,40 \%$.

8.- Se sigue la clasificación adoptada en muchos trabajos empíricos sobre la clasificación de las empresas según el tamaño del activo: muy pequeñas (<p25), pequeñas (p25-p50), medianas (p50-p75), grandes (p75-p90) y muy grandes ( $2 p 90)$.

9.- Debido a la dificultad de obtener la ratio de solvencia para cada banco, se utiliza el cociente K/A como variable proxy de la solvencia. 


\section{Tabla 4. Estructura del balance y cuota de mercado, según tamaño del activo, $2008-2013$ (1)}

\begin{tabular}{|c|c|c|c|c|c|c|}
\hline & \multirow[t]{2}{*}{ Total } & \multicolumn{5}{|c|}{ Tamaño del Activo } \\
\hline & & $<p 25$ & p25-p50 & p50-p75 & p75-p90 & $>p 90$ \\
\hline $\mathrm{N}^{\circ}$ de entidades & 15 & 6 & 2 & 3 & 2 & 2 \\
\hline Media del activo (millones de euros) & $6.225,1$ & $1.076,5$ & $1.969,0$ & $4.421,1$ & $7.003,0$ & $27.855,4$ \\
\hline \multicolumn{7}{|l|}{ Cuota de mercado } \\
\hline Activo & 100,0 & 6,9 & 4,2 & 14,2 & 15,0 & 59,7 \\
\hline Créditos a la clientela & 100,0 & 5,7 & 3,8 & 12,6 & 14,7 & 63,1 \\
\hline Depósitos a la clientela & 100,0 & 6,7 & 4,4 & 13,7 & 14,6 & 60,6 \\
\hline \multicolumn{7}{|l|}{ Composición del Activo } \\
\hline Caja y depósitos en bancos centrales & 1,14 & 0,75 & 0,86 & 1,21 & 0,55 & 1,34 \\
\hline Cartera de negociación & 0,26 & 0,07 & 1,12 & 0,31 & 0,41 & 0,17 \\
\hline Otros activos financieros a valor razonable & 0,05 & 0,03 & 0,01 & 0,13 & 0,01 & 0,05 \\
\hline Activos financieros disponibles para la venta & 9,99 & 12,79 & 14,47 & 10,58 & 10,36 & 9,12 \\
\hline Inversiones crediticias & 80,58 & 74,91 & 75,23 & 81,61 & 83,60 & 80,61 \\
\hline Del que: Crédito a la clientela & 74,02 & 60,81 & 67,29 & 65,84 & 72,59 & 78,33 \\
\hline Participaciones & 0,17 & 0,27 & 0,05 & 0,07 & 0,43 & 0,13 \\
\hline Activo material & 2,00 & 2,17 & 2,73 & 2,08 & 1,97 & 1,93 \\
\hline Resto activo & 5,79 & 9,02 & 5,53 & 4,00 & 2,67 & 6,65 \\
\hline \multicolumn{7}{|l|}{ Composición del Pasivo } \\
\hline Cartera de negociación & 0,11 & 0,04 & 0,06 & 0,19 & 0,29 & 0,06 \\
\hline Otros pasivos financieros a valor razonable & 0,04 & 0,00 & 0,01 & 0,28 & 0,00 & 0,00 \\
\hline Pasivos financieros a coste amortizado & 90,86 & 91,43 & 89,52 & 91,33 & 89,82 & 91,05 \\
\hline Depósitos de bancos centrales & 5,16 & 2,24 & 6,67 & 3,78 & 0,00 & 7,02 \\
\hline Depósitos de entidades de crédito & 8,43 & 17,92 & 6,09 & 16,36 & 16,12 & 3,67 \\
\hline Depósitos de la clientela & 72,90 & 70,69 & 75,63 & 70,37 & 70,82 & 74,09 \\
\hline Débitos representados por valores negociables & 3,41 & 0,00 & 0,00 & 0,06 & 2,14 & 5,16 \\
\hline Pasivos subordinados & 0,22 & 0,00 & 0,23 & 0,08 & 0,00 & 0,33 \\
\hline Otros pasivos financieros & 0,75 & 0,57 & 0,89 & 0,68 & 0,74 & 0,78 \\
\hline Provisiones & 0,23 & 0,16 & 0,09 & 0,33 & 0,23 & 0,23 \\
\hline Resto pasivo & 8,75 & 8,37 & 10,31 & 7,87 & 9,66 & 8,66 \\
\hline \multicolumn{7}{|l|}{ Patrimonio Neto } \\
\hline Del cual: Fondos propios & 7,29 & 7,21 & 7,46 & 7,03 & 8,59 & 7,02 \\
\hline
\end{tabular}

(1) Los cálculos se han realizado sobre las medias de cada entidad durante el período 2008-2013.

FUENTE: Unacc. Elaboración propia. 


\section{Tabla 5. Composición y cuota de mercado, según tamaño del activo y nivel de capitalización, 2008-2013 (1)}

\begin{tabular}{|c|c|c|c|c|c|c|}
\hline & \multirow[t]{2}{*}{ Total } & \multicolumn{5}{|c|}{ Tamaño del Activo } \\
\hline & & $<$ p25 & p25-p50 & p50-p75 & p75-p90 & $>\mathrm{p} 90$ \\
\hline \multicolumn{7}{|l|}{$\mathrm{K} / \mathrm{A}<8 \%$} \\
\hline $\mathrm{N}^{\circ}$ de entidades & 11 & 5 & 1 & 3 & 0 & 2 \\
\hline Media del activo (millones de euros) & $8.202,7$ & $1.051,9$ & $1.990,1$ & $4.421,1$ & - & $27.855,4$ \\
\hline \multicolumn{7}{|l|}{ Cuota de mercado } \\
\hline Activo & 81,6 & 5,6 & 2,1 & 14,2 & - & 59,7 \\
\hline Créditos a la clientela & 81,6 & 4,5 & 2,0 & 12,6 & - & 63,1 \\
\hline Depósitos a la clientela & 81,9 & 5,4 & 2,2 & 13,7 & - & 60,6 \\
\hline \multicolumn{7}{|l|}{$\mathrm{K} / \mathrm{A}>8 \%$} \\
\hline$N^{\circ}$ de entidades & 4 & 1 & 1 & 0 & 2 & 0 \\
\hline Media del activo & $4.288,3$ & $1.199,2$ & $1.947,8$ & - & $7.003,0$ & - \\
\hline \multicolumn{7}{|l|}{ Cuota de mercado } \\
\hline Activo & 18,4 & 1,3 & 2,1 & - & 15,0 & - \\
\hline Créditos a la clientela & 17,8 & 1,2 & 1,9 & - & 14,7 & - \\
\hline Depósitos a la clientela & 18,1 & 1,3 & 2,2 & - & 14,6 & - \\
\hline
\end{tabular}

(1) Los cálculos se han realizado sobre las medias de cada entidad durante el período 2008-2013.

FUENTE: Unacc. Elaboración propia.

Resumiendo, el proceso de concentración llevado a cabo en el sector de cooperativas de crédito ha producido una segmentación en dos grupos: las más grandes (>p90) y el resto de entidades (<p90), abarcando, las primeras, una cuota de mercado del $60 \%$ en el activo, volumen de crédito a la clientela y total de depósitos a la clientela.

Además, existen diferencias en la estructura del activo según el tamaño de la entidad: las de mayor tamaño mantienen un mayor porcentaje de créditos y un menor porcentaje de títulos que las de menor tamaño. Sin embargo, no se observa un comportamiento diferencial entre entidades de distinto tamaño en la composición del pasivo, siendo muy dependientes (más del 70\%) de los depósitos a la clientela.

Por último, aunque no hay relación entre el tamaño de la entidad y su nivel de capitalización, los cooperativas más grande ${ }^{10}$ (>p90) están menos capitalizadas que el resto, evidenciando problemas de solvencia que, bajo condiciones adversas en el entorno, pueden provocar una reducción significativa en la oferta crediticia. 
4.2. Análisis econométrico de la respuesta heterogénea de las cooperativas de crédito a la crisis actual, según el tamaño y el grado de capitalización

Según Kishan y Opiela (2000), los determinantes de la oferta crediticia y del acceso a otras formas de financiación se recogen mediante la siguiente especificación econométrica:

$$
y_{i t}=\alpha_{i}+\sum_{k=1}^{K} \beta_{k} x_{k i t}+\gamma R_{t}+u_{i t}
$$

donde la variable $y_{\mathrm{it}}$ se refiere tanto el logaritmo de los créditos a la clientela como el logaritmo de otras formas de financiación no sujetas a reservas; las variables $X_{\text {kit }}$ incluyen otras partidas del balance: el logaritmo de los depósitos a la clientela, el cociente entre títulos y activo (proxy del grado de liquidez), el cociente entre otras fuentes de financiación y activo y el grado de capitalización (fondos propios/activo) -para la regresión de los créditos-; el logaritmo del activo, el logaritmo de los depósitos a la clientela y el grado de capitalización-para la regresión de otras formas de financiación-; la variable $\mathrm{R}_{\mathrm{t}}$ es un indicador del signo de la política monetaria y de las facilidades/dificultades de obtener liquidez inmediata -el tipo de interés a un día de los depósitos no transferibles del mercado interbancario-; $\alpha_{i}$ es la constante que recoge la existencia de efectos individuales, es decir, de comportamientos diferenciadores entre individuos pero que sólo afectan a la constante, siendo las pendientes parciales iguales para todos; $y$, por último, $u_{i t}$ es el término de perturbación. La tabla 6 presenta los resultados de las estimaciones del modelo anterior.

\section{Tabla 6. Determinantes de la oferta de crédito y del acceso a otras fuentes de financiación, 2008-2013}

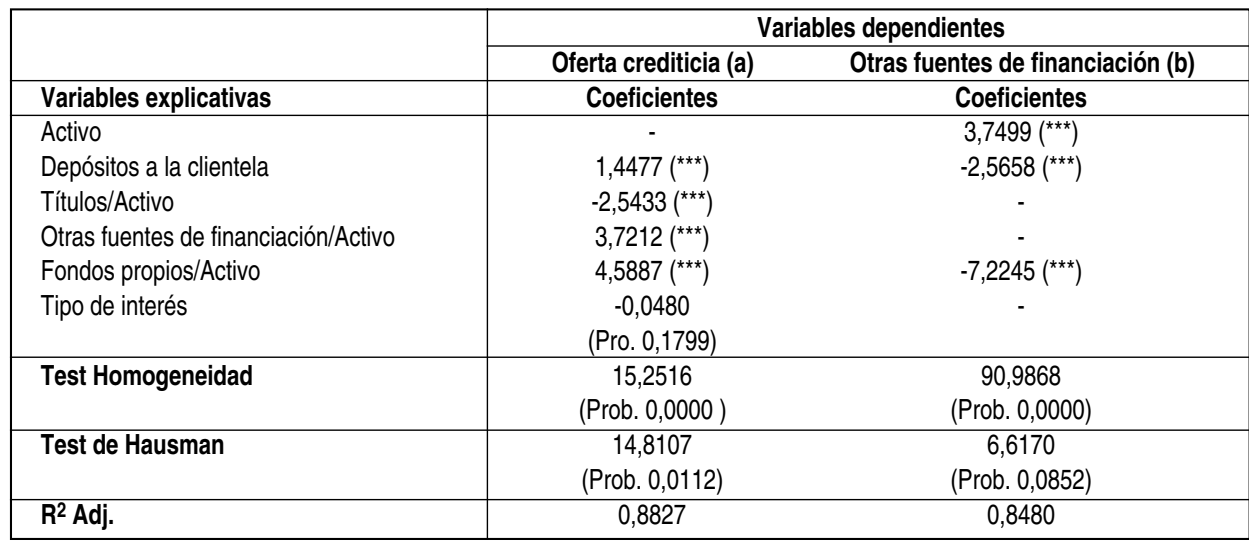

Nota: $\left({ }^{*}\right)$ nivel de significatividad del $\left.10 \%,{ }^{* *}\right)$ nivel de significatividad del $5 \%$ y $\left(^{* \star *}\right)$ nivel de significatividad del $1 \%$. (a) Modelo de Efectos Individuales Fijos. (b) Modelo de Efectos Individuales Aleatorios. 
Respecto a la oferta crediticia de la banca cooperativa durante el período 2008-2013:

- Se demuestra la respuesta heterogénea de la oferta de crédito entre las cooperativas de crédito -rechazándose la hipótesis nula de homogeneidad mediante el test de homogeneidad ${ }^{11}$.

- Además, dicho comportamiento diferencial depende de las características recogidas en la estimación, ya que se trata de un modelo de efectos individuales fijos -rechazándose la hipótesis nula de efectos aleatorios mediante el test de Hausman-.

- Según el signo de los coeficientes estimados, se puede concluir que las cooperativas de crédito que han mantenido un porcentaje menor de activos líquidos en sus balances, que han accedido más fácilmente a otras fuentes de financiación distinta de los depósitos a la clientela y que han mantenido un alto grado de capitalización, han podido incrementar su oferta crediticia en mayor medida que el resto de cooperativas.

- Analizando los efectos individuales (tabla 7), son las cooperativas más grandes (p75-p90 y $>$ p90) y las más capitalizadas $(K / A>8 \%)$-dentro de las cuales están las de los percentiles p75-p90- las que reducirían más la oferta crediticia ante un shock adverso. Este resultado se justifica, en primer lugar, porque las cooperativas de crédito más grandes son las que mantienen un porcentaje menor de títulos líquidos en su activo, siendo insuficientes para amortiguar una caída en el crédito; en segundo lugar, porque la demanda de crédito es más elástica para las entidades de mayor tamaño, sustituyendo los grandes clientes la financiación bancaria por otros medios (acciones, obligaciones, pagarés de empresa, etc.); $y$, en tercer lugar, el cumplimiento de las nuevas exigencias de capital desincentivan a las entidades a ofrecer más crédito, prefiriendo otros activos menos arriesgados.

11.- El test de homogeneidad permite contrastar la hipótesis nula de que los individuos de la muestra tienen un comportamiento idéntico, considerándose el modelo como un "pool de datos", frente a la hipótesis alternativa de que sí existe un comportamiento heterogéneo entre los individuos, considerándose el modelo como de "efectos individuales". 


\section{Tabla 7. Estimación de los efectos individuales en la oferta de crédito y en el acceso a otras fuentes de financiación}

\begin{tabular}{|c|c|c|}
\hline & \multicolumn{2}{|c|}{ Variables dependientes } \\
\hline & Oferta crediticia & Otras fuentes de financiación \\
\hline Efectos individuales & $\left(\alpha_{i}\right)$ & $\left(\alpha_{i}\right)$ \\
\hline \multicolumn{3}{|l|}{ Tamaño } \\
\hline$<\mathrm{p} 25$ & 1,1199 & 0,1750 \\
\hline p25-p50 & $-0,2524$ & $-0,6588$ \\
\hline p50-p75 & 0,0286 & 0,2819 \\
\hline p75-p90 & $-0,7235$ & 0,3895 \\
\hline$>$ p90 & $-2,4268$ & $-0,4745$ \\
\hline \multicolumn{3}{|l|}{ Capitalización } \\
\hline $\mathrm{K} / \mathrm{A}<8 \%$ & 0,0513 & $-0,1507$ \\
\hline$K / A>8 \%$ & $-0,1411$ & 0,5165 \\
\hline
\end{tabular}

Respecto a otras formas de financiación que ha utilizado la banca cooperativa durante el período de crisis:

- Se demuestra la respuesta heterogénea en el acceso a otras fuentes de financiación entre las cooperativas de crédito -rechazándose la hipótesis nula de homogeneidad mediante el test de homogeneidad-.

- Pero dicho comportamiento diferencial no depende de las características recogidas en la estimación, ya que se trata de un modelo de efectos individuales aleatorios -aceptándose la hipótesis nula de efectos aleatorios mediante el test de Hausman-.

- Según el signo de los coeficientes estimados, se obtiene, por un lado, que a mayor tamaño más facilidad para compensar una reducción en su volumen de depósitos accediendo a otros instrumentos de financiación, y de este modo, mantener o aumentar su oferta crediticia; pero, por otro, el signo del grado de capitalización no es positivo, ya que cabría esperar que un mayor nivel de fondos propios permitiese acceder más fácilmente a otras fuentes. Este resultado puede ser explicado porque el grado de capitalización no es una buena variable proxy de la capacidad de las entidades para acceder al mercado de otras fuentes de financiación -lo correcto sería utilizar la ratio de solvencia para medir los problemas de selección adversa $y$, por tanto, la accesibilidad a este mercado-. 
- Sin embargo, analizando los efectos individuales (tabla 7), son las cooperativas comprendidas en los percentiles p75-p90, que son a su vez las más capitalizadas ( $K / A>8 \%)$, las que accederían más fácilmente a otras fuentes de financiación ante un shock adverso, pudiendo mantener o aumentar su oferta crediticia. Mientras que las cooperativas de mayor tamaño (>p90), que están infracapitalizadas, tienen más problemas de obtener financiación ante una perturbación negativa.

Resumiendo, si bien se ha demostrado que ha existido un comportamiento asimétrico en las cooperativas de crédito, durante el período 2008-2013, respecto a la oferta crediticia y al acceso a otros recursos financieros (aceptándose en ambos casos un modelo de Efectos Individuales), la evidencia no es concluyente sobre el impacto del tamaño y el grado de capitalización en la justificación de dicha respuesta diferencial.

No obstante, se puede afirmar que las cooperativas de crédito más pequeñas ( $<\mathrm{p} 25)$, que a su vez mantienen un bajo nivel de capitalización, han podido incrementar su oferta crediticia y acceder a otras formas de financiación en la crisis financiera actual; mientras que las de mayor tamaño (p75-p90 y $>p 90$ ), han reducido su oferta crediticia debido, por un lado, a un mayor esfuerzo en las dotaciones de capital (p75-p90) y, por otro, al participar en procesos de fusión y de absorción (>90).

Por último, dado que las decisiones que las cooperativas de crédito han adoptado en este proceso de ajuste -en términos de aumentar la concentración en el sector y adecuarse a los requerimientos de capital y de una mayor dotación a provisiones-, han repercutido en la cuenta de resultados de las entidades, se ha llevado a cabo una estimación de los determinantes de la tasa de rentabilidad de las cooperativas de crédito, ROA, durante 2008-2013.

Siguiendo el modelo propuesto por Pérez, Maudos y Pastor (1999), el cual recoge como variables explicativas de la tasa de rentabilidad el porcentaje del margen bruto sobre el total del activo, el grado de eficiencia operativa, el peso de las operaciones fuera del balance y el grado de apalancamiento, la estimación presentada en este trabajo trata de recoger dos hechos relevantes que han modificado la cuenta de resultados de las cooperativas de crédito en estos años: un aumento de las provisiones por pérdidas de deterioro de activos y un incremento en las dotaciones de capital.

Los resultados obtenidos son los siguientes (véase la tabla 8):

- Las cooperativas de crédito se comportan de manera diferencial en la generación de beneficios -rechazándose la hipótesis nula de homogeneidad mediante el test de homogeneidad-.

- Dicha respuesta heterogénea depende de las características recogidas en la estimación, ya que se trata de un modelo de efectos individuales fijos-rechazándose la hipótesis nula de efectos aleatorios mediante el test de Hausman-. 
- La tasa de rentabilidad de las cooperativas de crédito depende:

i) En primer lugar y de forma negativa, de las dotaciones a provisiones de las pérdidas por deterioro de activos financieros. Recuérdese el enorme esfuerzo que han realizado las cooperativas de crédito en términos de provisiones, absorbiendo, por término medio, el $23 \%$ del margen bruto generado, siendo casi el 100\% en el 2012 .

ii) En segundo lugar y de forma positiva, de la generación del margen bruto, cuyo cociente entre el total del activo puede interpretarse como el precio, neto de costes financieros, que cobra la entidad bancaria por unidad de producto, el cual depende del poder de monopolio que tenga la entidad en función del grado de competencia que exista en el mercado. La elevada concentración que se ha producido en el sector cooperativo -en el que sólo dos cooperativas de crédito satisfacen el $60 \%$ del mercado-y, por tanto, la reducción de la competencia permite a las grandes entidades aumentar este precio neto.

iii) En tercer lugar y de forma negativa, del grado de capitalización, es decir, las nuevas exigencias sobre requerimientos de capital y requisitos de solvencia han supuesto un gran esfuerzo para las cooperativas de crédito, aumentando de forma creciente la dotación de capital y reservas (véase el gráfico 5), entrando en un proceso de desapalancamiento el cual está afectando de forma negativa a la tasa de rentabilidad.

iv) $Y$, por último y de forma negativa, de los costes operativos medios (Gastos de Explotación/Margen Bruto). Las ganancias de eficiencia que se observan en el conjunto de las cooperativas de crédito desde 2011 gracias a los procesos de integración (véase el gráfico 7) están contribuyendo a una mejora de la rentabilidad.

- Analizando los efectos individuales (tabla 9), las cooperativas medianas y grandes (p50-p75, p75-p90 y >p90) son las que están en mejores condiciones de obtener una tasa de rentabilidad mayor, gracias a su mayor poder de monopolio y a sus esfuerzos reduciendo sus costes unitarios; mientras que las cooperativas más capitalizadas y solventes $(K / A>8 \%)$ están mejor posicionadas para absorber shocks adversos y presentar beneficios mayores. 

Tabla 8. Determinantes de la tasa de rentabilidad, 2008-
2013

\begin{tabular}{|lc|}
\hline & Determinantes de la rentabilidad \\
& ROA(a) \\
\hline Variables explicativas & Coeficientes \\
\hline Margen Bruto/Activo & $0,8150\left(^{* \star \star}\right)$ \\
Gastos de Explotación/Margen Bruto & $-0,003\left(^{* \star}\right)$ \\
Provisiones/Activo & $-1,0197\left(^{\star \star *}\right)$ \\
Fondos propios/Activo & $-0,1327\left(^{\star \star *}\right)$ \\
\hline Test Homogeneidad & 10,1413 \\
& $($ Prob. 0,0000$)$ \\
\hline Test de Hausman & 72,8653 \\
& $($ Prob. 0,0000$)$ \\
\hline $\mathbf{R}^{2}$ Adj. & 0,9685 \\
\hline
\end{tabular}

Nota: $\left.{ }^{*}\right)$ nivel de significatividad del $10 \%$, $\left.{ }^{(*)}\right)$ nivel de significatividad del $5 \%$ y ${ }^{(* *)}$ nivel de significatividad del $1 \%$. (a) Modelo de Efectos Individuales Fijos.

\section{Tabla 9. Estimación de los efectos individuales en la rentabilidad (ROA)}

\begin{tabular}{|lc|}
\hline & $\begin{array}{c}\text { Determinantes de la rentabilidad } \\
\text { ROA }\end{array}$ \\
\hline Efectos individuales & $\left(\alpha_{\mathrm{i}}\right)$ \\
\hline Tamaño & \\
$<$ p25 & $-0,0016$ \\
p25-p50 & $-0,0011$ \\
p50-p75 & 0,0016 \\
p75-p90 & 0,0023 \\
$>$ p90 & 0,0011 \\
\hline Capitalización & \\
\hline K/A $<8 \%$ & $-0,0004$ \\
K/A $>8 \%$ & 0,0011 \\
\hline
\end{tabular}




\section{5.- Conclusiones}

A lo largo de lo expuesto en los epígrafes anteriores se ha analizado cómo han resistido las cooperativas de crédito españolas a la crisis financiera a lo largo del periodo 2008-2013, dentro del marco global de cambios regulatorios acontecidos en el sistema bancario español.

Respecto a las características propias del proceso de reestructuración, se extraen las siguientes conclusiones:

- Con cierto retraso respecto de los mercados de referencia internacional, la estructura de las medidas adoptadas se han desarrollado sobre dos líneas básicas: acelerar el proceso de concentración bancaria y reducir la tipología de entidades de depósito a dos figuras, bancos y cooperativas de crédito.

- Desde un enfoque cronológico, se distinguen cuatro fases de reestructuración. A lo largo de ellas se ha pretendido desde facilitar el acceso a la liquidez; siendo las cajas de ahorro las protagonistas, ya que las cooperativas de crédito sólo accedieron al 3,17\% de las inyecciones de liquidez.

Sin duda la figura de la SIP ha demostrado su idoneidad en la consecución del objetivo de reestructuración y concentración. El resultado de estas operaciones de consolidación ha sido una reducción drástica en el censo de entidades de depósito, especialmente en las cajas de ahorros -un $72 \%$ menos-, seguido de las cooperativas de crédito con un $49 \%$ menos.

Finalmente, los RDL 2/2012 y18/2012 inauguran la fase actual de saneamiento de las entidades crediticias respecto de sus activos más problemáticos.

Teniendo en cuenta que este proceso de reestructuración se ha basado, por un lado, en mecanismos de fusión y de integración -aumentando la concentración del sector-y, por otro, en ajustes en el balance con los consiguientes efectos sobre la cuenta de resultados de las cooperativas, se ha aportado evidencia empírica del comportamiento asimétrico de las cooperativas de crédito durante el período 2008-2013, aunque los resultados son ambiguos respecto a la relevancia del tamaño y del grado de capitalización de las cooperativas de crédito. 
Utilizando una metodología basada en datos de panel, se han obtenido los siguientes resultados:

- Las cooperativas de crédito que han mantenido un porcentaje menor de activos líquidos en sus balances (p50-p75, p75-p90 y >p90), que han accedido más fácilmente a otras fuentes de financiación distinta de los depósitos a la clientela y que han mantenido un alto grado de capitalización, han podido incrementar su oferta crediticia en mayor medida que el resto de cooperativas.

- Las cooperativas de crédito más grandes ( $p 75-p 90$ y >p90) y las más capitalizadas (K/A > 8\%) son las que reducirían más la oferta crediticia ante un shock adverso.

- El grupo de cooperativas de crédito de tamaño grande (p75-p90), que son a su vez las más capitalizadas (K/A > 8\%), son las que accederían más fácilmente a otras fuentes de financiación ante un shock adverso, pudiendo mantener o aumentar su oferta crediticia. Mientras que las cooperativas de mayor tamaño (>p90), que están infracapitalizadas, tienen más problemas de obtener financiación ante una perturbación negativa.

- El efecto neto del tamaño de activo y del nivel de capitalización es ambiguo, ya que si bien sí son determinantes de la oferta crediticia y del acceso a otras fuentes de financiación, no son relevantes para justificar el comportamiento asimétrico observado en las cooperativas de crédito.

- Sin embargo, ambas dimensiones sí justificarían las respuestas asimétricas observadas en la tasa de rentabilidad, ya que, las cooperativas medianas y grandes (p50-p75, p75-p90 y >p90) son las que están en mejores condiciones de obtener una tasa de rentabilidad mayor, gracias a su mayor poder de monopolio y a sus esfuerzos reduciendo sus costes unitarios; mientras que las cooperativas más capitalizadas y solventes $(K / A>8 \%)$ están mejor posicionadas para absorber shocks adversos y presentar beneficios mayores. 


\section{Bibliografía}

ARELLANO, M. \& BOND, S. (1991): "Some tests of specification for panel data: Monte Carlo evidence and an application to employment equations", Review of Economics Studies, 58, 277-297.

BANCO DE ESPAÑA (2012): Memoria de la supervisión bancaria en España, 2011.

BELMONTE, L.J. \& CORTÉS, F.J. (2010): "La concentración del sector de cooperativas de crédito en España”, CIRIEC-España, Revista de Economía Pública, Social y Cooperativa, 68, 223-246.

BERNANKE, B.S. \& BLINDER, A.S. (1988): "Is It Money or Credit, or Both, or Neither? Credit, Money, and Aggregate Demand", AEA Papers and Proceedings, 78:2, 435-439.

CARBÓ, S. (2010): "Presente y futuro del modelo de cajas de ahorros en España", CIRIEC-España, Revista de Economía Pública, Social y Cooperativa, 68, 167-182.

ENCINAS, B. (2010): "Las Cajas Rurales frente a la crisis. Comportamiento de los diferentes modelos de negocio en función de la conformación de su Eficiencia Operativa", CIRIEC-España, Revista de Economía Pública, Social y Cooperativa, 68, 81-110.

EHRMANN, M. et al. (2001): "Financial systems and the role of banks in monetary policy transmission in the Euro area", Documento de Trabajo N. 0118, Banco de España, Servicio de Estudios.

FAJARDO, G. (2011): "How viable are spanish credit cooperatives after the recent bank capitalization and restructuring regulations?", CIRIEC-España, Revista de Economía Pública, Social y Cooperativa, 73, Special Issue, 151-170.

GUTIÉRREZ, M. \& PALOMO, R.J. (2012): "Los sistemas institucionales de protección como respuesta de la banca cooperativa española ante la crisis: hacia la búsqueda de la eficiencia en su integración", CIRIEC- España, Revista de Economía Pública, Social y Cooperativa, 76, 27-50.

GUTIÉRREZ, M., PALOMO, R.J. \& ROMERO, M. (2012): "La expansión territorial como factor motivador de la reestructuración del sistema financiero español: el caso de las cajas de ahorro y las cooperativas de crédito", REVESCO, Revista de Estudios Cooperativos, 107, 7-34.

GUTIÉRREZ, M., PALOMO, R.J. \& FERNÁNDEZ, G. (2013): "Las cajas de ahorro españolas: ¿una pretendida reordenación bajo criterios de racionalidad económica y social?", CEDE, Cuadernos de Economía y Empresa.

HERNANDO, I. \& MARTíNEZ-PAGÉS, J. (2001): "Is There a Bank Lending Channel of Monetary Policy in Spain?", Documento de Trabajo, N. 0117, Banco de España, Servicio de Estudios.

KASHYAP, A.K. \& STEIN, J.C. (1995): "The Impact of Monetary Policy on Banks Balance Sheets?", Carnegie-Rochester Conference Series on Public Policy, 42, 151-195. 
KASHYAP, A.K. \& STEIN, J.C. (2000): "What do a Millon Banks Have to Say about the Transmission of Monetary Policy?", American Economic Review, 90:3, 407-428.

KASHYAP, A.K., STEIN, J.C. \& WILCOX, D.W. (1993): "Monetary policy and credit conditions: evidence from the composition of external finance", The American Economic Review, 83:1, 78-98.

KING, S.R. (1986): "Monetary transmission through bank loans or bank liabilities?", Journal of Money, Credit and Banking, 18:3, 290-303.

KISHAN, R.P. \& OPIELA, T.P. (2000): "Bank size, bank capital, and the bank lending channel", Journal of Money, Credit, and Banking, 32:1, 121-141.

MARÍN, S., GRAS, E. \& ANTÓN, M. (2011): "Financial information and restructuring of spanish savings banks in a context of crisis. Changes in the regulation, content and evolution of FROB", CIRIECEspaña, Revista de Economía Pública, Social y Cooperativa, 73, Special Issue, 96-126.

PALOMO, R.J., SANCHIS, J.R. \& SOLER, F. (2010): "Las entidades financieras de la economía social ante la crisis financiera: un análisis de las cajas rurales españolas", REVESCO, Revista de Estudios Cooperativos, 100, 101-133.

PÉREZ, F., MAUDOS, J. \& PASTOR, J.M. (1999): Sector bancario español (1985-1997). Cambio estructural y competencia, Caja de Ahorros del Mediterráneo (CAM).

PIZARRO-BARCELÓ, R. (2011): El canal del crédito bancario en la política monetaria. Una aplicación al caso español, Editorial Académica Española, LAP LAMBERT Acedemic Publishing GmbH \& Co. KG.

ROMER, C.D. \& ROMER, D.H. (1990): "New Evidence on the Monetary Transmission Mechanism", Brookings Papers on Economic Activity, 1, 149-213.

STIGLITZ, J.E. \& WEISS, A. (1981): "Credit rationing in markets with imperfect information", American Economic Review, 71:3, 393-410.

THAKOR, A.V. (1996): "Capital Requirements, Monetary Policy, and Aggregate Bank Lending: Theory and Empirical Evidence", The Journal of Finance, Ll:1, 279-324.

UNACC (2011): 40 años de la Unacc. El nuevo mapa del sistema financiero, Edita: Unión Nacional de Cooperativas de Crédito (Unacc), Madrid.

VAN DEN HEUVEL, S.J. (2002): Banking Conditions and the Effects of Monetary Policy: Evidence from U.S. States, mimeo. 
